\title{
Traditional Moral Values of the Oromo of Ethiopia: A Philosophical Appraisal of Gada System Synopsis of a PhD Dissertation*
}

\author{
Tenna Dewo $^{* *}$
}

\section{Introduction}

This is a report of my $\mathrm{PhD}$ dissertation titled "Traditional Moral Values of the Oromo of Ethiopia: A Philosophical Appraisal of Gada System". The dissertation ventures to accomplish three missions - one is the mission of bringing the traditional moral values of the Oromo people to light, the other is to critically evaluate the content of these values and the third is to demonstrate the applicability of philosophical inquiry to the concrete life and relations of human beings.

The entire text of the dissertation is composed of six chapters. At the end of each chapter there are critical analyses, conclusions, references and notes. Finally at the end of the whole body of the dissertation there is bibliography and appendix. The appendix contains the pictures of some of the elderly informants who orally shared their knowledge of the traditional moral values of the Oromo society. The first chapter attempts to lay out the problems that instigated the research, the general problems that the dissertation addresses, the methods that the researcher employs, and a conceptual and theoretical groundwork for the subsequent chapters.

\section{Background}

Human persons should not be looked upon as beings explainable only in terms of facts, but also as beings of value- orientations and systems. In knowledge, among the many important things, people are concerned with facts and values. Barry (1983: 93) observed that philosophers distinguish between a factual and value judgments. A factual judgment describes an empirical relationship or reality whereas value judgment assesses the worth of objects, acts, feelings, attitudes and even people. We make choices, decisions or

\footnotetext{
" PhD dissertation defended in October 2009, Panjab University, India

** Assistant Professor, Department of Philosophy, Addis Ababa University
} 
preferences depending on the values of the thing under consideration. "The value system we acquire and develop affects our attitudes, preferences, goals and aspirations." (Tripathi 2003: 22) "In short, the living space we create for our selves, and the quality of our lives, are determined by our system of life." (Ibid: 23) Values express the worth, importance or the utility of things, actions, behaviors, relations, systems, etc.

It is thought very often that value is not what is concretely lived but an abstract concept that should be contemplated. But this is not true. We value or evaluate daily the value of many things. On the basis of the value we ascribe to each, we develop certain attitudes towards them. We value things, because we value ourselves too. Without values the survival and flourishing of humanity is just precarious. Moral value is fundamental to all forms of value. According to Pojman, moral value is a set of "rules that are necessary for human survival and flourishing." (2005:78) It is with reference to this value that human actions and behaviors are evaluated as right or wrong, good or evil. But human kind have not studied and developed values as much as it has been doing with facts. Particularly traditional moral values have not caught the attention of scholars as much as they should.

Undertaking research on values is a daunting task to venture into. Yet it is the essential trait of human reality that ought to be explored. Moral value that pervades almost all human actions and behaviors is even more daunting for research than other forms of value. This is due to its complexity that emanates from the intricate nature of human beings, their relationships and mental states. Although I was aware of the intricacies of the subject, I convinced myself to undertake research in the indigenous moral values of the Oromo society, for my $\mathrm{PhD}$ dissertation. I would like to mention only four reasons that inspired me to study the traditional moral value of the Oromo society. First, it is largely the unexplored (or unexamined) aspect of the people's life. Two, it is primarily a pervasive element in the lives of all societies. Third, research provokes the interest of searching into what is there in the storehouse of the traditional values. Forth, there is a necessity of bringing the treasure of philosophy to the objective reality of human society.

One of the severe follies of humankind arises mainly from its failure to critically examine itself. Although the necessity of self-knowledge has ever seized the mind of people, it has not yet acquired the place it deserved. With hazy eyes, blurred vision and unclear mind to oneself the possibility of creating a better society is certainly uncertain. Many of the atrocities that humanity unfortunately experienced might be the results of lack of self-knowledge. The confinement of human cognition to the knowledge of external things alone cannot meaningfully address human problems. Knowing what and who we are internally is equally important since it is the knowledge of how brilliant or foolish, strong or weak, good or bad, right or wrong we were and we are.

\section{Analysis of the Problems}

Many of the elements that constitute the personalities of the Oromo people are implanted in their traditions. Traditional moral values, in particular, have tremendous role in shaping their lives and personality. Viewed from this angle, tradition has an enormous contribution to what and who they were in the past, what and who they are at the present. Not only external factors shape human reality, but also those which are put in them in the form of 
thoughts, spiritual doctrines, philosophical ideas, customary norms, moral judgments and beliefs. Traditional moral values are embedded in all of these.

The internal reality of humankind is intricately knitted together through infinite threads of values and facts. People focus, however, more on things that are external to them than on those that constitute their internal life. Facts of the external things are more known than moral values that have tremendous role in shaping, developing and guiding human personality. Leaving traditional moral values unexplored is tantamount to blinding oneself to one's own reality. I am of the opinion that the key to all the challenges that unceasingly haunt Ethiopia and its people lie, by and large, in the traditional moral values of its people. From the present experience it can be said that either people have not made this tradition to flourish into modern form or conversely, tradition has not made people to flourish.

Every tradition has its strong and weak sides. It is impossible to think that they are entirely useless since they may contain dynamic elements that can serve the good purposes of human beings, and in the same logic it is unreasonable to consider them as entirely useful because they may embrace apathetic components. Some traditions may hurt more than they do help; others may help more than they hurt. The point is to understand the extent to which they help or hurt. Thus, it sounds to argue that no indigenous value should be considered useless before it is critically evaluated. The uncritical approach people have towards traditions is harmful in at least three ways. First, we cannot be aware of the constraints that traditional values impose on us. We take them for granted when in fact they contain a lot of unreasonable, irrational, superstitious, unchecked beliefs and ideas. Second, we might not be enlightened about the good and bad dimensions the traditional moral values entail. In the light of the modern culture of the West, we may think that our traditional values are entirely archaic and burden that should be avoided. Contrarily, they may embrace universally valid ingredients. Third, we cannot develop self knowledge that instills sense of confidence in ourselves. Lack of sound knowledge of what constitute our reality often generates identity crisis. That is why the thesis begins with the hypothesis that traditional moral values should not be entirely accepted or rejected. Rather, they must critically be analyzed and synthesized.

In the context of western philosophy, tradition and modernity are very often antagonized. The word 'tradition' very often connotes negative meaning whereas the term modernity is loaded with a positive one. Modernity is seen as good, safe, humane and rational whereas tradition is seen as devoid of these good qualities. But this may not be true. Modernity should not make us think that everything in the storehouse of our tradition is backward and harmful, and everything in the culture of the West is good. Tradition also should not blind us to the good sides of modernity. This is one of the basic reasons why my dissertation sets out from the belief that tradition is not virtually useless and modernity is not totally good.

We need to reflect on traditional values for three major reasons. One, it is important to know how rational and relevant they are in addressing human questions and solve problems; two, it is important to clearly grasp and disclose to what extent they hinder human progress and third, to figure out the place they hold in the entire value system of the world. Traditional values largely express a common level consciousness. They may, on one hand, contain superstitious and false beliefs, and rational and valid forms of thought on the 
other. Viewed from this angle, undoubtedly there is a necessity of investigating traditional moral values. But which subject is reasonably appropriate to undertake this investigation?

\section{Philosophical Inquiry in Tradition}

If there is a domain of investigation to which the traditional moral values of societies fall as objects of enquiry, it is primarily philosophy. The predominance of undefined and unrefined concepts, unexamined and unfounded beliefs in traditional value systems, is very obvious. Traditional state of life is a life-situation where complex challenges remain critically unchecked. We cannot use hard sciences for checking these parts of human reality. We cannot also afford to leave them unexplored. Conceptual analysis is inevitable for such investigation. In this scenario the service of philosophy is tremendously important.

How philosophy could be applied to life and social relations has been one important point of contention. People think very often that philosophy deals only with abstract things. It appears as if it is inapplicable to the concrete life and world of man. Indeed man has philosophized much more about things that are non-humans. We have, therefore, applied either little or no philosophy to some aspects of human reality. This is not because philosophy has failed to provide us with knowledge, but rather humankind has not used philosophy as much as it is required.

Just as the known is in the realm of sciences, the unknown is always in the territory of philosophy. Philosophy is basically rooted in human reality, the reality which is composed of things that are accessible and inaccessible to sciences of hard facts. We assume that we have knowledge of things that are accessible to sciences. But what could be said about those aspects of human reality that are inaccessible to physical sciences? Should we leave it as a part of human reality to which we remain ignorant? The explorations of those aspects of life that are inaccessible to these sciences are left to philosophy.

Philosophy has the capacity of extending the cognitive power of humans to aspects of life and reality that other disciplines cannot reach, and also the ability to integrate or synthesize the fragmented knowledge of different fields. However, it must be underlined that those issues that are inaccessible to hard sciences and unknown are not necessarily and always elsewhere but also here in human reality. Traditional moral values, for example, are one of those that are, in philosophical terms, less known aspects of humans. This is what makes the critique of philosophy towards traditional moral values, very imperative.

A great deal of philosophical concepts is analyzed over and over again. Indeed this is not bad. But it is not as urgent as the philosophical studies of those things that have never been un-reflected upon. The traditions of many societies of the present world are largely un-reflected upon. It means the life of the bulk of human population of the present day world is unexamined.

Philosophy is the criticism of the common level consciousness. Traditional forms of thought are appropriate subjects for philosophy to study. I am of the opinion that one of the grave problems why the human world fails to adequately solve its problems is because it does not properly and sincerely use philosophy to understand and explain itself as much as required. 
This study aims to contribute to both the life of man and the development of philosophy. Its approach bridges the gap between the reality of man and the knowledge of philosophy. Its effort is to show the applicability and meaningfulness of philosophy to the concrete life of humans. The more humanity brings philosophy to light, the better it makes it a lively and meaningful area of knowledge; and the more philosophy becomes living, the deeper the knowledge humanity acquires about itself.

\section{Methodology and contents of the dissertation}

One important question is how the traditional values of a specific society can be studied philosophically? In terms of the method it employs, the thesis may slightly deviate from the conventional way of making philosophical investigation. In both conventional and nonconventional reflections, analysis is the core method. In the conventional one it is philosophical concepts that are often analyzed. What makes the approach of this thesis different from that of the conventional one is that the objects of its reflection are the traditional moral values.

The dissertation is based on the data obtained from sociological, anthropological, historical, and linguistic studies and also from the field research. It shifts from the conventional analysis of philosophical concepts to the analysis of data reflecting the empirical realities of people. The basic motif is to use the rich analytical method of philosophy to develop genuine knowledge of the human self and reality. In other words, the major objective of this thesis is not to report the traditional moral value of the Oromo people as it is in itself but to reflect on the strength or rationality of its foundation. To that effect, the data collected are philosophically analyzed and synthesized in order to sift the truth from falsity, the rational from the non-rational of this value.

The thesis makes philosophical analysis in the form of critical assessment at three levels - first, right in the context of a particular subject or topic, second at the end of a chapter and third in the last chapter of the thesis. The critical assessment focuses primarily on the points or reasons that are philosophically unpalatable, irrelevant, logically or rationally inconsistent. Although undertaking a research of this nature is tedious, the researcher believes that at the end of the day it is a rewarding intellectual endeavor, since the humanity of humankind lies more in the reality of the commonplace than it does in the transcendence.

Chapter two is all about the subject of the study. It is titled "The Oromo of Ethiopia". The physical, geographical, demographic and ethnographic (linguistic, religious, history, moral, the myth of common origin and socio-political systems) features of Ethiopia as a country and of the Oromo as a people are briefly given in sections 1, 2, and 3 of the chapter. The dissertation looked into these features because they are value-loaded features.

Chapter three is titled "Gada System: A Storehouse of Values". The chapter is concerned with the genesis, evolution and the nature of Gada System. Gada is the comprehensive system that the Oromo people had been developing and using at least for five centuries before the end of the $19^{\text {th }}$ century. As a comprehensive system of thought it integrates political, social, religious and moral values. This is what makes it a storehouse of values. The chapter is divided into three major parts. The first part briefly presents some 
basic features of the system, the second part attempts to show the philosophical nature of the system and the third describes how Gada consistently organizes the society in to various social and political platforms for the purpose of enabling every person play an important role in leading a harmonious and peaceful life.

There is a point of philosophical interest in the second part of this chapter. It is devoted to the exploration of whether the Gada system is a religion, politics, philosophy or any nebulous and uncritical form of thought. To figure out whether it is a philosophy or not, it requires addressing one philosophical debate being undertaken currently on the existence and features of African philosophy. There are two diametrically opposite philosophical trends in response to the question whether such a thing as "African philosophy" exists or not. One trend posits and the other trend negates (or at least doubts) the existence of African philosophy. To examine whether Gada is a philosophy or not, the thesis first attempts to unravel the theoretical issues debated between these two trends.

After having examined the arguments advanced for and against, the dissertation finally came up with the conclusion that the essential feature that makes philosophy what it is, is its critical and rational nature. Thus, although it is logically fallacious to argue that all the African traditions have philosophical stuff, it is impossible to deny that there are some traditions that are philosophical at their own basis. The Oromo Gada is one of the African traditions that is primarily a philosophy.

Although it is a complex system of thought in which there are rational, non-rational and irrational forms of ideas, its criticality, rationality, comprehensiveness, coherence, logical consistence and harmony in addressing the important questions of life and relations makes it plausibly a philosophy. Predominantly it is a moral, social and political philosophy since it is concerned more with the issues of values of life than knowledge of facts. The construction of peaceful and harmonious life or in general the creation of good life is the ultimate aim that it wants to achieve.

The third part of the chapter attempts to explain the political philosophy of the Gada system. In its political dimension, the Oromo Gada System addresses the problem of leadership. It describes how the society should organize itself across the age-sets for the purpose of training people, electing leaders, governing the society, monitoring officials and counseling people. Upon analysis, the dissertation has arrived at the conclusion that the Gada of the Oromo is a desirable system of rule. It was the system in which the Oromo people not only taught and learnt how to harmoniously live together, but also how leaders should peacefully come to power and leave this power, how rulers ought to rule and subjects to be ruled.

Chapter four is devoted to the traditional moral values of the Oromo society, known as safuu. The title of the chapter is "Moral Values of Oromo". Safuu (the moral value of Oromo) is the underpinning principle of Gada. It is thought that if the rules of safuu are not observed all sorts of human pursuits would be chaotic, precarious and injurious. The thesis attempts to disclose that safuu defines what virtues to pursue, what vices to avoid, what rights to enjoy and what responsibilities to discharge. In this sense, safuu is a moral category that prescribes what human actions and behaviors ought to be. The chapter is divided into twelve sections, and several sub-subsections. It discusses the meaning of safuu in its various shades in order to disentangle its moral meaning. Its various aspects are 
expressed through different topics. The chapter attempts to bring out to light the very foundation of safuu. The actions, characters or behaviors that safuu appreciates are shown. The fact that the core concepts of safuu are rooted in the human values such as human life, dignity, right, freedom, interest, etc. are discussed. What an individual human being is to the society and human society to the individual is described. The concepts of good, truthfulness, honesty and peace are raised and discussed as the core virtues of safuu. Concepts of friendship, Oromo work ethic and social pathologies are also figured out.

Safuu shares certain features in common with the virtue ethics of the ancient Greeks. In virtue ethics moral rightness or wrongness, goodness or badness is rooted in the character of the moral agent. Similarly, in the Oromo safuu character of a person occupies the central place. In this sense, in both the virtue ethics of the Greeks and the safuu of the Oromo the internal character of the moral agent is decisively emphasized. For both the ultimate purpose is to produce excellent persons who could act or behave out of goodness. There is link between the character of a person and the acts and behaviors of that person. A person of good character does not act in a morally wrong way unless and otherwise by accident. With the same logic, a person of bad character does not act in a morally right way unless forced by accident or external conditions. Both moral good and moral evil are motivated by the character of the moral agent. Safuu prescribes what we ought to do and not to do, what we ought to be and not to be in order to promote good life. It teaches that persons destroy the path to the attainment of good life, by doing what they ought not to do, or by being what they ought not to be. Evils do not only block the road to good life but also threaten the survival of life.

This chapter also extensively and intensively expounds the Oromo traditional concept of peace. There are three major reasons for acclaiming this concept in particular. One, indeed peace is generally a moral concept. It holds key place in the Oromo traditional values (safuu). Second, apparently of all the important subjects, philosophy seems to have given less attention to peace, when it should have made it deserve more attention. In this sense, there is a necessity of inspiring philosophical reflection on peace. Third, the tragic experience of the current world calls upon philosophy to undertake analytical and practical endeavors on peace. What could be more important for philosophy to reflect upon than the situation in which humankind is panicking because of war and violence, terror and bloodshed?

Chapter five is about the practical application of the moral principles and rules propounded in the safuu and Gada of the Oromo. It is entitled "Moral Concerns for Others and Oneself". In their relationships people indispensably treat one another. The point of morality is whether the treatment is fair or unfair, beneficial or detrimental. How each of us would like to be treated by others may differ from how we would like to treat others. Plausibly most of us like to be treated fairly. But the doubt is whether most of us would like to treat others the way we want to be treated for ourselves. This is the crux of the problem at which morality strikes. Certainly the way the Oromo treat others and would like to be treated by others depends on their indigenous moral value. This chapter is divided into three major parts each of which is further broken into sections and subsections. The sections of the first part are mainly about how the Oromo practically treat one another as individuals or groups and other people (non - Oromo). The section begins with 
the moral life of families where the relations and treatment are very immediate and intimate. One could be a husband or wife, son or daughter, child or parent, brother or sister in relation to the other. Standing in certain relation to the other certainly means treating others and being treated by these others. For the Oromo it is safuu that governs the relations and treatment of the family members more than legal rules do. Safuu explains the caring, sharing and loving attitude of each member towards the other. This treatment is critically examined in order to understand the moral quality of their actions, aspirations and characters.

Data collected from field research and archival sources clearly show that the Oromo treat others the way they like to be treated by others for themselves. When they individually or collectively think of treating others they first put one question to themselves. "How would we like others to treat us?" Certainly, like any human beings, the Oromo would like to be treated in a morally desirable way. They believe that if whatever they like other people to do to them is something morally desirable then they do not have any moral justification to treat others in a morally undesirable way. This can be understood from their concept of humanity, the fair treatment they offered to others in their interaction and assimilation with other people.

The section also examines how moral the Oromo were in treating themselves. They do not ascribe superior values to themselves and inferior values to others. They value others as much as they do themselves. They had used to change others into Oromo (Oromized) and themselves into others (De-Oromized). The question is how moral they were in making others embrace Oromo-identity and in receiving the identity of others. They used no force or violence to change others as well as themselves. Peaceful actions and tolerance were the core of this transaction. This was because they ascribed neither superior nor inferior values to themselves as well as to others.

The other section of the chapter discusses how the Oromo have been treated by others particularly by the ruling regimes of Ethiopia in the last one century. The subsections reveal that the Oromo have not been treated the way they would like to be treated. They have not been treated even the way they used to treat others. An attempt is made to specifically disclose the distortion of Oromo history, the denigration and mystification of the Oromo identity, the intellectual, cultural and institutional alienation committed against them, political marginalization and suppression of language. In view of this injustice and immoral treatment inflicted upon them the Oromo have not realized the immense potential they had.

The third section attempts to bring to light what attitude the Oromo people eventually developed in reaction to the unfair treatment inflicted upon them. In sum, this chapter attempts to critically examine, whether these treatments solved moral problems or created them - whether they made life better or worse.

The sixth chapter consists of critical assessments and concluding remarks of the dissertation. The chapter attempts to clear up the strength and weakness of the Oromo traditional moral values. Their strength is evaluated with reference to their universalizablity, dynamism, workability and relevance. And their weakness is explained in their failure to satisfy this. I am convinced that these can be applicable to human condition without provoking contradiction with the universal ideals of humanity. The several 
sections and sub-sections of this chapter venture to reveal the strong sides of the Oromo traditional moral values. Humanism, selflessness, tolerance, the power of integrating people, the democratic culture and life that Gada and safuu entail, the place and value that the Oromo tradition give to peace, and the appreciation for the rule of law are shown as some of the strong and prominent sides of the Oromo traditional moral values. The major weak sides figured out are failure to assess the repercussions of their moral acts and the lack of literary culture.

The last section of the chapter is about the implications and suggestions. Although moral values are relevant to and inseparable from human life and relations they have not been taken care of as much as they take care of human life and interest. Probably this is what has created the grave moral-crisis that is threatening the current world. The thesis suggests what philosophic, institutional and academic efforts should be exerted to restore and further strengthen the desirable aspects of the Oromo morality and avoid the undesirable ones. In the sub-sections of this section the moral being-ness of human being, its development in all possible aspects, the integration of moral values of different human societies, the necessity of conducting research on moral values, the incorporation of value education in school curriculum and the need of institutionalizing morality are emphasized.

\section{Conclusion}

In this dissertation an attempt has been made to critically examine the traditional moral values of the Oromo people. These traditional moral values are the reflection of the Oromo ways of life. We can discover a great deal about how the Oromo think, treat other people, would like to be treated, and to what extent their thought is consistent with the contemporary value systems of the world. I started the research with a lot of doubts in mind about the importance and validity of traditional moral values. But even then I was certain about one thing. If it does not serve good purpose undoubtedly it works for the converse. If it does not positively help, it negatively hurts. In both ways it is relevant since there is a need to promote positive and avoid negative. Knowing one's negative part for rectification, is as important as knowing one's positive side. It was this that gave me an impetus to come out of the state of uncertainty.

With the help of the data collected from historical, sociological, anthropological and field work I finally managed to come up with the modest understanding of the Oromo morality. The objectives of bringing the Oromo moral values to light and testing their validity through philosophical analysis are accomplished. The relevant and strong sides of this traditional morality are the universal ingredients that can stand the test of time, and hence are part and parcel of the whole ideal system of humanity. Although the way it had been managed and transmitted makes it traditional, the quality of its content is largely modern. It is more of a living than a dying system.

From this, the study has come up with a conclusive remark that nothing is more relevant to make the social transformation of the indigenous people possible than their own indigenous value system, of which moral value is the core component. Humanity should 
unceasingly and critically evaluate its value systems in order to avoid destroying the good with the bad and the retention of the bad with the good.

\section{References}

Barry, V. 1983. Philosophy: A Text with Readings. Belmont: Wadsworth Publishing Company.

Grayling, A. C. 2005. The Heart of Things: Applying Philosophy to the $21^{\text {st }}$ Century. Phoenix.

Legesse, Asmarom. 2000. Oromo Democracy: An Indigenous African Political System. Asmara: The Red Sea, Inc.

Levine, D. N. 1974. Greater Ethiopia: The Evolution of Multi-ethnic Society. Chicago and London: The University of Chicago Press.

Patrick, G. T. Introduction to Philosophy. New Delhi: Surjeet Publications.

Pojman, P. L. 2005. How Should We Live? An Introduction to ethics: Belmont, CA: Thompson/Wadsworth.

Sharma, R.N. 1993. Introduction to Ethics. Delhi - 111 007: Surjeet Publications

Tripathi, A. N. 2005. Human Values. New Delhi: New Age International Publishers. 